15.44-fold increased risk for AVN, compared with patients without these risk factors $(p<0.001)$. RERI, AP, and $S$, which define the strength of interactions between two risk factors, were 9.01 (95\% confidence interval (CI) 1.30-16.73), 0.58 (95\% Cl $0.36-0.81)$, and 2.66 (95\% Cl 1.42-4.99), respectively, supporting the presence of synergistic interactions in the development of symptomatic AVN in our Korean lupus cohort.

Abstract THU0356 - Table 1. Synergistic effect of total cumulative steroid dose and use of immunosuppressants in development of AVN in SLE patients

\begin{tabular}{|c|c|c|c|c|}
\hline & $\begin{array}{l}\text { No. patients } \\
\text { with AVN }\end{array}$ & $\begin{array}{l}\text { No. patients } \\
\text { without AVN }\end{array}$ & $\begin{array}{c}\mathrm{OR}^{\mathrm{a}} \\
(95 \% \mathrm{Cl})\end{array}$ & $\mathrm{p}$-value \\
\hline $\begin{array}{l}\text { Total cumulative steroid dose } \leq 20 \mathrm{~g} \\
\text { and immunosuppressants (-) }\end{array}$ & 11 & 314 & 1.00 & \\
\hline $\begin{array}{l}\text { Total cumulative steroid dose }>20 \mathrm{~g} \\
\text { and immunosuppressants (-) }\end{array}$ & 17 & 168 & $\begin{array}{c}3.08 \\
(1.40- \\
6.81)\end{array}$ & 0.005 \\
\hline $\begin{array}{l}\text { Total cumulative steroid dose } \leq 20 \mathrm{~g} \\
\text { and immunosuppressants }(+)\end{array}$ & 18 & 121 & $\begin{array}{c}4.34 \\
(1.99- \\
9.49)\end{array}$ & $<0.001$ \\
\hline $\begin{array}{l}\text { Total cumulative steroid dose }>20 \mathrm{~g} \\
\text { and immunosuppressants }(+)\end{array}$ & 64 & 134 & $\begin{array}{l}15.44 \\
(7.64- \\
31.19)\end{array}$ & $<0.001$ \\
\hline RERI & & & $\begin{array}{c}9.01 \\
(1.30- \\
16.73)\end{array}$ & \\
\hline AP & & & $\begin{array}{c}0.58 \\
(0.36- \\
0.81)\end{array}$ & \\
\hline$S$ & & & $\begin{array}{c}2.66 \\
(1.42- \\
4.99)\end{array}$ & \\
\hline
\end{tabular}

AVN: avascular necrosis; SLE: systemic lupus erythematosus; OR: odds ratio; $\mathrm{Cl}$ : confidence interval; RERI: relative excess risk due to interaction; AP: attributable proportion; S: synergy index

a. Odds ratios were adjusted for sex, age and disease duration.

Conclusions: An individual risk assessment for AVN development should be made prior to and during treatment for SLE, especially in patients with high-dose corticosteroid and immunosuppressant use regardless of clinical manifestations and disease activity.

Disclosure of Interest: None declared

DOI: 10.1136/annrheumdis-2018-eular.3438

\section{THU0357 FEATURES ASSOCIATED WITH LOSS TO FOLLOW-UP IN THE YEAR PRIOR TO DEATH IN PATIENTS WITH SYSTEMIC LUPUS ERYTHEMATOSUS: A RETROSPECTIVE ANALYSIS FROM A NATIONAL REFERRAL CENTRE}

${ }^{1}$ I. Padjen, M. Erceg ${ }^{2}$, M. Cerovec ${ }^{1}$, M. Bakula ${ }^{1}$, M. Mayer ${ }^{1}$, R. Stevanovic ${ }^{2}$, B. Anic ${ }^{1}$. 1 Department of Internal Medicine, Division of Clinical Immunology and Rheumatology, University Hospital Centre Zagreb and University of Zagreb, School of Medicine; ${ }^{2}$ Croatian Institute of Public Health, Zagreb, Croatia

Background: Loss to follow-up in the year prior to death may lead to underrecog nition and underreporting of systemic lupus erythematosus (SLE) as a cause of death of lupus patients.

Objectives: We aimed to assess the extent and features associated with loss to follow-up in the year prior to death in a group of 90 deceased SLE patients from our tertiary centre.

Methods: We retrospectively analysed 90 SLE patients (68 females) followed-up at our centre, deceased from 2002 to 2011 . Patients were $\geq 18$ years of age at death and fulfilled $\geq 4$ classification criteria of the American College of Rheumatology (ACR). The cause and place of death were identified by matching patient data from our department's SLE registry with data from the National Death Database. Patients were considered lost to follow-up in the year prior to death (LTF) if the time span between the last visit to our centre and death exceeded 1 year. Other patients were considered to be under regular follow-up (RGF).

An extensive set of parameters was compared between the LTF and RGF groups: demographics, ACR classification criteria, cumulative damage according to the Systemic Lupus International Collaborative Clinics (SLICC)/ACR index, as well as causes of death. Frequencies were compared using the chi-square and Fisher's exact test, and continuous variables using the t-test and Mann-Whitney U-test.

Results: We identified 35/90 patients in the LTF group (29 females). The time span between the last visit to our centre and death of LTF patients ranged from $>1$ to 3 years. Compared to the RGF group, LTF patients were diagnosed at a later age (mean $\pm S D$ : $54 \pm 15$ vs. $44 \pm 17$ years, $p=0.006$ ), while there was no difference in disease duration (median of 11 years, IQR of 5-15 years in the RGF group vs. median of 7 years, IQR of $5-15$ years in the LTF group, $p=0.285$ ). The
LTF and RGF groups did not differ in the count of ACR criteria (median of 5, IQR of 4-6 vs. median of 6, IQR of $5-7, \mathrm{p}=0.053$ ) and cumulative damage (median damage of 3 , IQR of $2-5$ vs. median of 5 , IQR of $3-8, p=0.068$ ).

Compared to the RGF group, LTF patients had a lower cumulative proportion of pericarditis (1/35 vs.16/55), proteinuria (10/35 vs. $30 / 55)$, hemolytic anaemia (1/ 35 vs. $10 / 55)$, thrombocytopenia (5/35 vs. $21 / 55)$ and Hughes syndrome (2/35 vs. $13 / 55)(p<0.05)$. Pulmonary damage and peripheral vascular damage were observed only in RGF patients (9/55 vs. $0 / 35, p=0.011$; and $8 / 55$ vs. $0 / 35$, $p=0.021$, respectively). LTF patients also had a lower proportion of cardiomyopathy $(7 / 35$ vs. $24 / 55, p=0.021)$

RGF patients died more frequently from active lupus compared to their LTF counterparts $(24 / 55$ vs. $2 / 35, p<0.001)$, while no difference was observed between the proportions of death from infections, cardiovascular diseases, malignancies and unknown causes (figure 1). SLE was reported in death certificates of 30/55 RGF patients compared to only $11 / 35$ LTF patients $(p=0.032)$. Compared to the RGF group, a lesser proportion of LTF patients died in the hospital (17/35 vs. $46 / 55$, $\mathrm{p}=0.004)$.

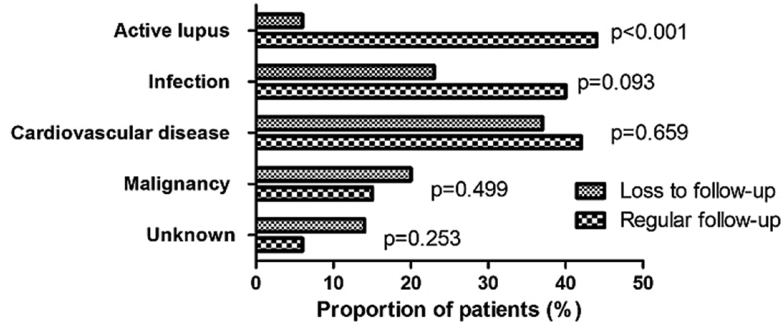

Abstract THU0357 - Figure 1. Causes of death according to follow-up status

Conclusions: A lower proportion of LTF patients exhibited features of active SLE over their disease course. This may have led to underrecognition of SLE as a contributor to death.

\section{REFERENCES}

[1] Calvo-Alen J, et al. Rheumatology 2005;44:1186-9.

[2] Abu-Shakra M, Novack V. J Rheumatol 2012;39:458-60.

Disclosure of Interest: None declared

DOI: 10.1136/annrheumdis-2018-eular.3567

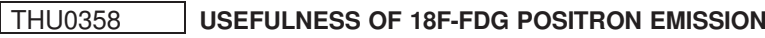 TOMOGRAPHY (PET) FOR LYMPHOMA DIAGNOSIS IN PATIENTS WITH PRIMARY SJÖGREN'S SYNDROME}

${ }^{1}$ J. Keraen, E. Blanc ${ }^{2}$, F. Besson ${ }^{3}$, M. Meyer ${ }^{3}$, V. Le Guern ${ }^{4}$, G. Nocturne', J. Henry ${ }^{1}$, R. Belkhir ${ }^{1}$, X. Mariette ${ }^{1}$, R. Seror ${ }^{1} .{ }^{1}$ Rheumatology, CHU du Kremlin Bicêtre, Kremlin Bicêtre; ${ }^{2}$ Nuclear imaging, Centre Chirugical Marie Lannelongue, Le Plessis Robinson; ${ }^{3}$ Nuclear imaging, CHU du Kremlin Bicêtre, Kremlin Bicêtre ${ }^{4}$ Internal Medicine, Cochin, Paris, France

Background: Primary Sjögren's syndrome (pSS) is the autoimmune disease having the highest risk of lymphoma. The differential diagnosis between benign and malignant lymphoproliferation is sometimes difficult. Among imaging procedures, 18F-FDG PET could be useful for that purpose.

Objectives: To compare 18F-FDG PET results between patients with and without lymphoma to identify PET pattern associated with lymphomas in pSS

Methods: Retrospective study conducted in 2 centres including pSS patients (according to ACR/EULAR 2016 criteria) who undergo 18F-FDG PET. We com pared PET abnormalities in patients with and without lymphoma, the PET having been done before any chemotherapy. Two independent readers analysed PET blind to lymphoma diagnosis. ESSDAI-PET score previously described by Cohen et al.[' was calculated.

Results: 45 patients were included; 15 had lymphoma: MALT ( $n=12)$, nodal marginal zone with plasmacytic differentiation $(n=2)$, diffuse large B-cell $(n=1)$. Patients with lymphoma had more frequently parotid gland swelling $(67 \%$ vs $20 \%$, $\mathrm{p}=0.003)$ and higher ESSDAI score (24 [13.5-29] vs $\left.9,^{5-20} \mathrm{p}=0.03\right)$, even after exclusion of lymphoma item $\left(19^{11-27}\right.$ VS $\left.9,{ }^{5-20} \mathrm{p}=0.03\right)$.

Compared to non-lymphoma patients, mean size $\left(45.5^{38-56} \mathrm{~mm}\right.$ vs. $40^{37-41} \mathrm{~mm}$ $\mathrm{p}=0.048$ ) and maximum standardised uptake value (SUVmax) of the parotid glands (5.6 [5-6.9] vs 3.8 [3.2-4.4]; $\mathrm{p}=0.001)$ were higher in lymphoma patients $53.3 \%$ of patients with lymphoma and $43.3 \%$ without lymphoma had lymph node FDG uptake, but neither their number nor their repartition or mean SUV differ between them. 